\title{
Reasonable limiting 7-day incidence per hundred thousand value in Germany
}

\author{
R. Schlickeiser ${ }^{1,2, *}$, M. Kröger ${ }^{3, * *}$ \\ ${ }^{1}$ Institut für Theoretische Physik, Lehrstuhl IV: Weltraum- und Astrophysik, \\ Ruhr-Universität Bochum, D-44780 Bochum, Germany, ORCID 0000-0003-3171-5079 \\ ${ }^{2}$ Institut für Theoretische Physik und Astrophysik, Christian-Albrechts-Universität zu Kiel, Leibnizstr. 15, D-24118 Kiel, Germany \\ ${ }^{3}$ Polymer Physics, Department of Materials, ETH Zurich, \\ Zurich CH-8093, Switzerland, ORCID 0000-0003-1402-671
}

(Dated: January 13, 2021)

\begin{abstract}
Based on the hospital capacities, facts from the past experience with the Covid-19 virus and the dark number of infections $D=10 D_{10}$ a reasonable limiting value of $170 / D_{10}$ for the monitored 7-day incidence per 100000 persons value (MSDIHT) in Germany is calculated. If the MSDIHT is held below this limiting value the German hospital system can cope with the number of new seriously infected persons without any triage decisions. A significant improvement to an almost complete testing of the population would lead to dramatic reduction of the current dark numer value to $D_{10}=0.1$ so that ten times higher MSDIHT values of 1700 are acceptable. Such a high limiting value would spare Germany from its currently imposed strict lockdown. The costs for such extensive and complete testing campaigns are highly justified as they are orders of magnitudes below the estimated economical costs of more than 3.6 billion Euros for each lockdown day.
\end{abstract}

Keywords: coronavirus; extrapolation; 7-day incidence value; Covid-19

In Germany the imposement of non-pharmaceutical interventions (NPIs) leading to partial and total lockdowns are justified with values of the so-called monitored 7-day incident per 100000 persons value - hereafter referred to as MSDIHTexceeding either 50 or 200 , respectively. The MSDIHT is given by the monitored number of new infections per 100000 persons summed over the last 7 days. With estimated costs

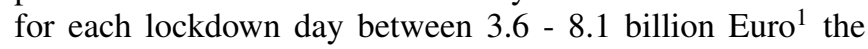
calculation of a reasonable MSDIHT value is of extreme importance.

In this little note we discuss how reasonable the values 50 or 200 are, based on the hospital capacities in Germany, the facts we know from our past experience with the Covid-19 virus and the dark number of infections $D$. However, due to incomplete testing the MDIHT does not agree with the true 7-day incident per 100000 persons value which is larger by the dark number factor $D$. In Germany this dark number has been estimated ${ }^{2}$ to be about $D=8.4 \pm 4.0$ by modeling simultaneusly the monitored death and infection rates during the first Covid-19 wave. In our considerations we will use scaled quantities so that our method can also be applied to other countries or smaller regions in each country.

Germany has about $B=28000 b$ breathing apparati or intensitive treatment beds $(b=B / 28000$ stands for the number of breathing apparati in units of 28000) so that in Germany $b=1$. The breathing apparati are typically occupied by seriously infected persons (SIPs) in intensive hospital care on average for about 14 days. Consequently, every day $B / 14=2000 b$ breathing apparati are available for new SIPs.

From our past experience with the Covid-19 virus ${ }^{3,4}$ we know that about 20 percent of the number $I$ of newly infected persons per day have symptoms (the other 80 percent

*rsch@tp4.rub.de, mk@mat.etz.ch have mild or no symptons), 5 percent have to be hospitalized and $1 h$ percent ( $h$ hereafter is adopted to be unity) need access to breathing apparati. Of these SIPS eventually every 2 nd person dies from the virus within the 14 days of intensive care which then corresponds to a mortality rate of $f=h / 200=0.005 h$. The German health system therefore can cope with $I=2000 b \times(100 / h)=200000 b / h$ newly infected persons per day.

Germany has a population of $N=83$ million persons corresponding to $830 N_{5}$ with $N_{5}=100000$ persons. The maximum capable incidence value per 100000 persons in Germany is then given by $M=I / 830=241 b / h$. Consequently, the corresponding true SDIHT is given by

$$
\mathrm{SDIHT}=7 M=1687 \mathrm{~b} / \mathrm{h}
$$

Adopting the dark number value $D=10 D_{10}$ we find that

$$
\mathrm{MSDIHT}=\frac{\mathrm{SDIHT}}{10 D_{10}}=\frac{170 b}{h D_{10}}
$$

is a reasonable value. This is significantly larger than the value of 50 .

We close with four final comments:

1) Germany has had already very high value of the SDIHT during the 2nd wave. Maximum death rates of 1100 per day have been reported, which with a fatality rate of $f=$ $0.5 h$ percent $=h / 200$ corresponding to $I=220000 / h$ per day and an SDIHT of $1855 / h$.

2) If in the future one would stick to an MSDIHT value of 50 it means that only about one third of the medical capacity in Germany will be used for the intensive treatment of Covid19 SIPs.

3) Only with more accurate and complete testing of the population the high dark number of $10 D_{10}$ can be reduced. In this case a higher MSDIHT value would be possible which at most 
equals the SDIHT value of $1687 b / h$. Such a high limiting value would spare Germany from its currently imposed strict lockdown. The costs for such extensive and complete testing campaigns are highly justified as they are order of magnitudes below the estimated economical costs of each lockdown day of more than 3.6 billion Euros.

4) The adopted fatality rate of $f=0.5 h$ percent $=h / 200$ implies that in the worst case (without the now available vaccination campaigns of the population) the total number of Covid-19 fatalities is $\eta f N=0.415 \eta h$ million persons in Germany. Recent epidemics modeling ${ }^{5,6}$ demonstrated wave-like epidemic outbreaks to occur only for value of $\eta=0.5$, so that in the worst case about 208000 persons in Germany in total die from Covid-19, in the absence of any vaccine. This large number is about a quarter of the typical annual number of deaths in Germany, and it is hopefully getting drastically reduced further not only by a successful vaccination program, but also by the obvious advantage that comes with the decrease of the dark number, the knowledge of being infected or not.

As we have scaled our determination of the limiting MSDIHT value with appropriate scaling parameters it is straightforward to apply this calculation also to other countries or regional areas of interest.
1. Dorn, F., Fuest, C., Göttert, M., Krolage, C., Lautenbacher, S., Link, S., Peichl, A., Reif, M., Sauer, S., Stöckli, M., Wohlrabe, K., Wollmershäuser, T., Die volkswirtschaftlichen Kosten des Corona-Shutdown für Deutschland: Eine Szenarienrechnung, ifoSchnelldienst 4, 29 (2020) (in German)

2. Schlickeiser, R., Kröger, M., Dark numbers and herd immunity of the first Covid-19 wave and future social interventions, Epidem. Int. J. 4, 000152 (2020)

3. Schlickeiser, R., Schlickeiser, F., A gaussian model for the time development of the Sars-Cov-2 corona pandemic disease. Prrdictions for Germany made on March 30, Physics 2, 164-170 (2020)

4. Schüttler, J., Schlickeiser, R., Schlickeiser, F., Kröger, M., Covid19 predictions using a Gauss model, based on data from April 2, Physics 2, 197-202 (2020)

5. Schlickeiser, R., Kröger, M., Analytical Solution of the SIRModel for the Temporal Evolution of Epidemics. Part A: Timeindependent reproduction factor, J. Phys. A: Math. Theor. 53, 505601 (2020)

6. Schlickeiser, R., Kröger, M., Analytical Solution of the SIRModel for the Temporal Evolution of Epidemics. Part B: Semitime case, J. Phys. A: Math. Theor., submitted (2021)

\section{DEUTSCHE ZUSAMMENFASSUNG:}

Basierend auf der Verfügbarkeit von Beatmungsgeräten in Kliniken, den medizinischen Erfahrungen aus der er- sten Covid-19 Welle und einer hohen Dunkelziffer an Neu-Infizierten wird ein Grenzwert von $170 / D_{10}$ für die gezählte 7-Tage Inzidenz pro 100000 Einwohner (MSDIHT) in Deutschland bestimmt. Falls der MSDIHT unterhalb dieses Grenzwertes gehalten wird, kann das deutsche Gesundheitssystem alle schweren Covid-19 Erkrankungen ohne Triage-Entscheidungen behandeln. Durch ein starke Reduktion der Dunkelziffer durch nahezu komplette Testverfahren der Bevölkerung auf Werte von $D_{10}=0.1$ wäre dann auch ein zehnmal höherer MSDIHT Grenzwert von 1700 akzeptabel. Ein so hoher Grenzwert würde Deutschland den gegenwärtigen Lockdown mit all seinen negativen Auswirkungen ersparen. Die Kosten für solche ausgedehnten und kompletten Tests sind hochgradig gerechtfertigt, da sie um Grössenordnungen unterhalb der geschätzten ökonomischen Kosten von mehr als 3.6 Milliarden Euro pro Lockdown-Tag liegen. 西 